\title{
El oscurecimiento de la conciencia sobre la Iglesia y la pérdida de identidad de los cristianos según G. B. Montini
}

\author{
KLAUS BERCKHOLTZ BENAVIDES* \\ Universidad Peruana de Ciencias Aplicadas (Perú) \\ k.berckh@gmail.com
}

\section{Resumen}

Con su fina sensibilidad para leer los "signos de los tiempos", G. B. Montini supo percibir, cuando servía pastoralmente en la arquidiócesis de Milán, que una de las grandes dificultades que enfrentaban entonces los cristianos era el oscurecimiento de la conciencia sobre la Iglesia y la creciente pérdida de su propia identidad. No sólo identificó este problema como uno de los principales desafíos pastorales de su ministerio, sino que en su magisterio episcopal ofreció diagnósticos, reflexiones y propuestas de solución. El análisis de ese corpus doctrinal, que aquí se realiza, sirve al mismo tiempo para realzar la riqueza de su un tanto olvidado pensamiento teológico y se presenta como una sugerente cantera para el aquí y ahora de la Iglesia.

Palabras clave: iglesia; conciencia cristiana; G. B. Montini; secularismo; arzobispo de Milán.

\section{The darkening of conscience about the Church and the loss of identity of Christians according to G.B. Montini}

\begin{abstract}
With his fine sensitivity to read the "signs of the times," G. B. Montini perceived, when he served pastorally in the Archdiocese of Milan, that one of the great difficulties faced by Christians at that time was the darkening of the awareness about the Church and the growing loss of their own identity. Not only did he identify this problem as one of the main pastoral challenges of his ministry, but in his episcopal magisterium he offered diagnoses, reflections and proposals for solutions. The analysis of this doctrinal corpus, which is performed here, serves at the same time to enhance the richness of his somewhat forgotten theological thought and is presented as a suggestive quarry for the "here and now" of the Church.
\end{abstract}

Key words: church; christian awareness; G. B. Montini; secularism; archbishop of Milan.

\footnotetext{
* Doctor en Teología por la Facultad de Teología Pontificia y Civil de Lima (FTPCL). Profesor en la Universidad Peruana de Ciencias Aplicadas (UPC). Ha publicado recientemente "Antecedentes eclesiológicos de G. B. Montini - San Pablo VI" (2019).
} 


\section{INTRODUCCIÓN}

Uno de los grandes desafíos que han venido enfrentando los miembros del Pueblo de Dios en los últimos tiempos es el oscurecimiento de su conciencia sobre qué es la Iglesia, lo que a su vez ha generado el paulatino desdibujamiento de los rasgos que la distinguen con características particulares e inconfundibles. Esta disminución de la conciencia eclesial va de la mano con la confusión que experimentan sus miembros con relación a sus respectivas vocaciones específicas y en su experiencia personal como cristianos. Como no podría ser de otra manera, ello encuentra asimismo proyección en las diferentes expresiones de su misión evangelizadora, para las que no se descubren ya razones suficientes y hasta se duda de su misma validez. Si bien se trata de un peligro que de alguna manera ha acechado a la comunidad de creyentes desde los albores del cristianismo, en las últimas décadas hemos presenciado cómo este fenómeno se ha acentuado y extendido.

Testigo privilegiado en la evolución de este proceso durante el siglo XX fue sin duda el Papa San Pablo VI, al que "todos los eventos más importantes del siglo lo hallaron como espectador, a veces incluso como protagonista" (Crivelli, 2002: 27), y a quien le tocó conducir la nave de la Iglesia en los años trascendentales del Vaticano II y del post-Concilio. Con su fina sensibilidad para leer los "signos de los tiempos", él supo percibir con nitidez los contornos de esta problemática incluso antes de ser elevado al solio pontificio, mientras servía como Pastor en la arquidiócesis de Milán, ofreciendo en sus escritos episcopales sugerentes reflexiones sobre el particular.

El propósito del presente artículo es analizar ese corpus doctrinal ${ }^{1}$, centrando la atención en lo que el Arzobispo Montini escribió sobre el oscurecimiento de la identidad por parte de los bautizados y la pérdida de la conciencia eclesial en los miembros de la Iglesia. Queremos asimismo mostrar cómo esta problemática constituyó para él uno de los principales desafíos pastorales que le cupo enfrentar. Así pues, repasaremos sus descripciones y análisis de la cuestión, algunas de las raíces que identificó y las maneras de hacerle frente que propuso, dentro de las que

1 Como fuentes de los textos de G. B. Montini citaremos sobre todo las recopilaciones que en su momento publicó el Arzobispado de Milán: Discorsi su La Chiesa (1962) [DsC]; Discorsi su la Madonna e su i Santi (1965) [DsMS]; algunas ediciones que de esos textos aparecieron en castellano: Dios presente en el mundo (1969) [DPM], o en italiano: Pasqua: la novità dell'amore (2010) [PNA]; y los volúmenes promovidos por el «Istituto Paolo VI» de Brescia, como sus Scritti fucini (2004) [SF] o la monumental edición crítica en cuatro volúmenes de sus Discorsi e scritti milanesi (1954-1963) (1997-1998) [DSM]. Las traducciones de los textos del italiano son nuestras. 
destacan su invitación a la conciencia bautismal y su exhortación a conocer, amar y suscitar el anhelo por formar parte de la Iglesia. En este recorrido, seremos más sucintos y esquemáticos a la hora de recoger sus diagnósticos, y, en cambio, dedicaremos un poco más de atención a la presentación de sus vías de solución, donde consideramos que se encuentra lo más original de su pensamiento.

$\mathrm{El}$ interés que nos mueve comprende al menos dos dimensiones. Por un lado, traer a la luz el magisterio episcopal de G. B. Montini, quien -en opinión de uno de sus estudiosos y luego colaborador- fue "uno de los grandes especialistas en temas eclesiales que ha conocido nuestro tiempo" (Calderón, 1964: 93). Se trata, como tendremos ocasión de ver, de un pensamiento desarrollado, rico en reflexiones y profundo, que lastimosamente es poco conocido y ha permanecido un tanto oculto. Y, por otro lado, a partir de ahí, queremos sugerir que desde ese bagaje doctrinal bien se puede iluminar el hic et nunc de la Iglesia, un aquí y ahora para el que, salvadas las pequeñas y grandes diferencias, resulta inspiradora la obra montiniana.

Hasta donde tenemos noticia, un análisis semejante no ha sido aún realizado. No obstante los diversos estudios sobre diferentes aspectos de su ministerio y magisterio episcopal, entre los que encontramos desde visiones de conjunto (Majo, 1983; Potestà, 1988; Acerbi, 1996; Crivelli, 2002; Bressan \& Maffeis, 2017) hasta aproximaciones a tópicos delimitados — como su labor y opciones pastorales (Manfredini, 1985; Seveso, 1989), la "Misión de Milán" (Campanini, 2000; Airò, 2001; Adornato, 2002), la liturgia (Biffi, 1987; Alzati, 2006), el clero (Kadzinski, 1998), la vida religiosa (Poli \& Crespi, 1998), el laicado (Vaccaro, 2004), el mundo del trabajo y de la empresa (Caprioli \& Vaccaro, 1989; Taccolini, 2004), la laicidad (De Giorgi, 2015) - e incluso ensayos sobre los que podrían ser considerados los principales retos apostólicos que le tocó enfrentar -como la modernidad (Manzoni, 1997; Valtolina, 1999) o los “alejados" (Formenti, 1983) - , no hemos hallado ninguno que ofrezca una mirada sobre sus reflexiones respecto a la pérdida de identidad de los cristianos y al desdibujamiento de la conciencia sobre la Iglesia en su etapa milane$\mathrm{sa}^{2}$, ni tampoco ninguno que proponga esta problemática como medular dentro de su proyecto pastoral.

\footnotetext{
2 Quizá el que más se aproxime al nuestro sea el artículo de Xeres (2004), pero su contenido está centrado en los laicos y en realidad aborda otros ángulos. Pizzonia (1981) y Cioli (1995) han realizado investigaciones afines, pero en el período correspondiente a su pontificado.
} 
1. El panorama CUltural y eClesial en tiempos Del ArZobispo MONTINI $^{3}$

La necesidad - $y$, en contrapartida, la falta - de una habitual introspección reflexiva concitó desde temprano la atención de G. B. Montini. En efecto, ya en 1918, en una de sus colaboraciones para la revista estudiantil La Fionda, cuando aún era un joven seminarista, subrayaba la importancia de cultivar el conocimiento propio para poder llevar adelante una vida verdaderamente humana, y, en su defecto, las tristes consecuencias que supone una existencia alejada de la propia interioridad:

La vida interior es la propia individualidad, la propia persona, el propio yo. Descuidarse de vivir la vida interior es renunciar a uno mismo. ¡Y cuántos abdican de este imperio subjetivo! Abdican ciegamente para vivir sólo con los ojos o con el cuerpo.

Con el alma, con el corazón, no saben vivir, porque tienen un espíritu estéril, sin un pensamiento que lo vivifique, que lo haga consciente de sí mismo. [...] ¿Qué conoces de la vida, tú que no te conoces a ti mismo? Tú que has comprimido en ti los impulsos que debían haberte llevado a lo alto, ¿ahora te lamentas de haber sido enviado entre abismos inextricables? Apagaste las luces que estaban en ti, ¿y ahora lloras por no ver estrellas sobre tu cabeza? (Montini, 1979: 39-40; ver 56)

Poco más adelante, en torno al año 1919, unas Notas personales que escribió en una pequeña libreta de bolsillo atestiguan una preocupación similar: "El hombre pasa su vida entre estos dos estados de ánimo: la inconsciencia del espíritu y el miedo". Y ello lo lleva a lamentar: "Qué pequeños son esos espíritus presa de las emociones del miedo o ahogados por la inconsciencia» (Montini, 1994: 10 y 11). De ahí que, para llegar a ser quienes estamos llamados a ser, para comprender en todo su alcance lo que constituye nuestra naturaleza, abogue por ahondar en la autoconciencia y el conocimiento propio.

\subsection{Una "época de confusión y debilidad"}

Este interés temático acompañará toda la vida de G. B. Montini, y con el correr de los años se multiplicarán sus consideraciones al respecto, tanto en puntualizaciones como en número, especialmente en el período

3 Escapa al propósito de este escrito ofrecer información histórica sobre la vida de G. B. Montini. Dentro de las muchas biografías que existen, remitimos para ello especialmente a las siguientes, que dedican particular atención a su período episcopal: Calderón (1963), De la Hera (2002), Tornielli (2009), Tettamanzi (2009), Adornato (2018). 
en el que ejerció su ministerio pastoral en Milán. La capital lombarda, centro económico e industrial de Italia, atravesaba en aquel tiempo, junto a toda la nación, por un efervescente proceso con grandes transformaciones sociales, culturales y espirituales que "incidieron no solamente en la organización general de la sociedad, sino también en la mentalidad, los estilos de vida, el mundo de los valores y, por lo tanto, en el hecho religioso mismo" (Campanini, 2000: 36). La coyuntura espiritual y eclesial no se presentaba nada halagüeña; al contrario - como le compartía al Papa San Juan XXIII en una carta que le enviara en diciembre de 1959-, la Iglesia afrontaba "esta época de confusión y debilidad" como un auténtico desafío evangelizador.

Un primer elemento que identifica el Cardenal Montini son los embates que provienen desde "fuera", ya sea de quienes cultivan alguna animadversión hacia la Iglesia, ya sea como parte de un ambiente cultural que ha ido perdiendo los valores cristianos y generando un contexto poco favorable a la vivencia de la fe:

Las filas de los adversarios del nombre de Dios parece que aumentan y se fortalecen; el laicismo y el anticlericalismo vuelven imperiosamente a estar de moda; la licencia de las costumbres, especialmente en la prensa y en los espectáculos, se hace amplia, insolente y desenfrenada; ideas y corrientes de dudosa bondad agitan y dividen las mismas filas de aquellos que deberían ilustrar y defender el nombre cristiano. (22/12/1959, en Capovilla, 1982: 116)

Hay quienes incluso, yendo aún más lejos, abogan por una desaparición de la comunidad eclesial, como resulta visible "por las exclusiones, por las opresiones, por las persecuciones con las que gran parte del mundo moderno quisiera finalmente liquidado el 'fenómeno Iglesia', como engorroso, superfluo, nocivo para el desarrollo de la sociedad" (DSM III, 10/6/1962: 5160). La Iglesia se presenta como una figura incómoda para una civilización que quiere no sólo definirse como laica, sino también romper con las instituciones religiosas y restringir su presencia, en todo caso, al ámbito privado.

Pero para Mons. Montini los apremios no se deben "en primer lugar al ataque de los adversarios declarados de la Iglesia, si bien éstos continúan presentes en sus preocupaciones" (Giovagnoli, 2004: 181). Más relevante para él es la situación ad intra Ecclesiae, que tampoco es del todo satisfactoria. Las estructuras y formas apostólicas existentes evidencian su insuficiencia - no sólo en número, sino también en estilos e iniciativas- para responder a las inquietudes que anidan en el corazón de los hombres y mujeres de ese tiempo. No son pocos los que se sienten ale- 
jados de la Iglesia, faltos de su compañía en sus preocupaciones cotidianas, incomprendidos en sus intereses y afanes diarios, por lo que, gradualmente, se van distanciando de ella, primero afectiva y racionalmente, luego también de hecho.

Para completar el panorama, desde comienzos de la década de 1950 la arquidiócesis ha ido viendo disminuidas sus fuerzas apostólicas "principalmente a causa de la cada vez más acentuada reducción numérica de los miembros del clero y de las comunidades religiosas" (Bressan \& Maffeis, 2017: 9), circunstancia que se irá agravando con el correr de los años. Así, pues, son cada vez menos los obreros para una mies que requiere cada vez más dedicación y cuidados.

En paralelo, la comunión eclesial se ve afectada por actitudes de muchos de "nosotros los católicos, nosotros que tenemos la fortuna y la responsabilidad de vivir dentro de la casa paterna". El panorama que describe es ciertamente sombrío, y no se circunscribe sólo a aspectos que quizá puedan ser considerados secundarios - como riñas internas o diferencias de opinión-, sino que afecta también a los vínculos visibles de la comunión en el Pueblo de Dios, con renuencias explícitas a la obediencia, invitaciones a la rebelión y desviaciones de la ortodoxia:

La necesidad y el deber de la concordia son débiles y han sido olvidados; la obligación y el honor de la disciplina se relajan y a menudo se traicionan; la función necesaria y próvida de la autoridad, discutida, criticada y a veces negada; se habla, como de una conquista a lograr, de un pluralismo de ideas sobre verdades indiscutibles del patrimonio doctrinal de la Iglesia; existe aquí y allá la ridícula audacia de hablar de la 'humilde desobediencia' a la Jerarquía, como de un derecho y de un genial redescubrimiento de la vida espiritual; se viviseccionan las claras y responsables instrucciones de la Autoridad eclesiástica para encontrar, por medio de sofismas y de casuística de libre examen, los argumentos para eludir el grave sentido de tales instrucciones. Falta un cordial y fiel 'sentido de la Iglesia'. (DSM III, 23/5/1963: 5830)

\subsection{Repercusión en la conciencia de los cristianos}

Un aspecto que preocupa sobremanera a su corazón de Pastor es que las circunstancias antes mencionadas tienen un natural impacto en los creyentes, quienes forman parte de esa misma sociedad efervescente y por ende no son inmunes a su influjo ni tampoco permanecen ajenos al espíritu de su tiempo. Uno de esos efectos se manifiesta en la disminución del vigor respecto a su propia identidad. No es éste, por cierto, un hecho que él considere marginal, sino más bien uno que merece particular vigilancia. Así lo expone, por ejemplo, en 1955, en la primera celebra- 
ción navideña que le tocó presidir como Arzobispo, al constatar con pesar que el "término 'cristiano' aparece hoy debilitado" y que los mismos creyentes, "en cuanto pueden, tratan de olvidarlo o diluirlo en otras fórmulas, laicas y nada comprometidas con las consecuencias necesarias de tipo práctico que el nombre cristiano lleva consigo" (DPM, 25/12/1955: 24). Para Mons. Montini queda claro que el Bautismo no se reduce a un sacramento de iniciación meramente "social" o protocolar, sino que debe hacerse vida, trasluciéndose en todas las dimensiones de la existencia.

Más explícito y severo se mostrará unos meses después, en abril de 1956, denunciando que muchos hijos de la Iglesia han desvanecido a tal punto su talante cristiano, que ya no se distinguen de quienes no han sido regenerados por las aguas bautismales, y su conducta dista tanto de la plenitud de la vida cristiana que parecen haberse mimetizado con el mundo:

Vemos ante todo que poca o ninguna diferencia distingue a los cristianos de los que no lo son. [...] ¿El cristiano se ha atenuado tanto, que ya no siente repugnancia alguna por asimilarse a ese mundo al que había renunciado en el bautismo, y experimenta de buena gana la fascinación de aquellos halagos del mal, de los cuales quería inmunizarse en el bautismo?

Uno de los grandes males de nuestro tiempo consiste precisamente en esto: ver que los cristianos no son cristianos, que el misterio de novedad y de coherencia a ellos comunicado en el bautismo de resurrección no es vivido por ellos, que la componenda, el respeto humano, la incoherencia, la ilogicidad, la infidelidad son la miserable supervivencia de una vocación a la perfección, a la santidad, a la plenitud cristiana. (PNA, 1/4/1956: 57; ver DSM I, 1152, 1466)

Son palabras duras, pero que grafican algunas de las actitudes que socavan la vida cristiana de muchos bautizados y los alejan de ser ese fermento que su carácter sacramental conlleva, pues si bien los cristianos están "en" el mundo, no pueden ser "de" él sin traicionar su vocación. Muestran, asimismo, la preocupación de un Pastor que sabe que, si la sal se vuelve sosa, pierde su razón de ser.

Indudablemente a Mons. Montini no se le escapa que la situación particular de cada uno es distinta. Por ello en 1955, al comenzar las visitas pastorales que como Ordinario le correspondía realizar a las parroquias de su arquidiócesis, propone una descripción más precisa. Ofreciendo entonces una sugerente clasificación que recuerda la parábola del sembrador (Mt 13,3-9.18-23), distingue "tres estadios de esta conciencia aletargada y adormecida”. En primer lugar, 
aquellos que son cristianos porque están inscritos así en el registro civil y porque el agua del Bautismo, sin que ellos se dieran cuenta y tuvieran ni voluntad ni méritos, ha corrido sobre sus frentes, pero luego, pero luego ya no lo recuerdan, pero luego no tienen ya ningún pensamiento, no tienen ningún escrúpulo, ningún temor de Dios, ningún recuerdo de esta gran fortuna, de este gran destino que compromete sus vidas individuales. Y lo olvidan, y viven como si hubieran sido despojados y emancipados de la dulce y salvadora ley del Señor. (DSM I, 8/9/1955: 393)

Junto a ellos está, en segundo lugar, el que escucha la voz del Señor y mantiene aún algunos vínculos -más formales que existenciales, más consuetudinarios que producto de una convicción profunda, pero vínculos, al fin y al cabo- con la comunidad eclesial, a la que

viene a ser bautizado, a ser bendecido, a marcar los momentos capitales de su vida con un rito sagrado: el matrimonio o la última despedida de esta vida, el funeral, etc., quiere todavía estar anclado a esta tradición cristiana. Pero también en este caso esta conciencia ya no está latente, sino que es intermitente; es una conciencia inestable, incoherente, no productiva. (DSM I, 8/9/1955: 394)

Y, por último, en tercer lugar, el grupo "de aquellos que tienen conciencia, de aquellos que todos los días profesan su sujeción, su obsequio a la ley cristiana, que rezan, que se confiesan, que tratan de ser lo que llamamos fieles". Pero hay algo de lo que muchas veces carecen: "Falta la aplicación de la vida cristiana. Son cristianos en la iglesia, no lo son más en el mundo. Son cristianos en determinados aspectos de sus vidas, no lo son en muchos otros. Son cristianos que han hecho, diría, un contrato con el Señor: 'Hasta aquí, sí; en el resto, no...”' (DSM I, 8/9/1955: 395; ver III, 4221). Para Mons. Montini, por tanto, la mera conciencia no es suficiente, sino que, para ser auténtica, debe traducirse en vivencia cotidiana, en aplicación práctica; una vivencia, además, que ha de abarcar todas las dimensiones y los momentos de la existencia, no sólo los principales o unos cuantos. De ahí que para él ninguna de estas tres categorías de cristianos -signados, es cierto, por el carácter bautismal, pero poseedores de una conciencia mutilada e incompleta que los conduce en la práctica a una existencia ajena a los criterios y valores evangélicos-, merecerá la alabanza, la bendición y el premio de Dios.

Ampliando su diagnóstico, el Arzobispo de Milán apunta que todo ello, como es lógico suponer, se ve reflejado a nivel conceptual en el desconocimiento cada vez mayor de las verdades fundamentales de la doctrina cristiana. Quienes han recibido el baño bautismal no saben bien en qué creen, no conocen su fe ni están capacitados para "dar razón de 
su esperanza" (ver 1Pe 3,15), no valoran el tesoro del que han sido hechos depositarios. Por esa razón, el Cardenal Montini advierte que

uno de los defectos más graves de los cristianos modernos, especialmente en nuestro país y sobre todo, me atrevería a decir, en los que pertenecen a las clases cultas, es la carencia de nociones religiosas precisas y completas y la consiguiente incertidumbre en torno a los principios fundamentales sobre la concepción de la vida y el mundo. (DPM, 25/12/1960: 85)

Al opacarse el conocimiento del depósito revelado, se da también, por supuesto, una ceguera espiritual respecto a lo que es propiamente la Iglesia, una seria dificultad para comprender cuál es su razón de ser y qué papel debe jugar tanto en la existencia concreta de sus hijos como en la sociedad civil en su conjunto. No sólo se mantienen las falsas oposiciones entre quienes se quedan únicamente en su dimensión externa o quienes acentúan unilateralmente su dimensión interna ${ }^{4}$, sino que, a la par, se va perdiendo la percepción de su origen, de su naturaleza teándrica, de su misión salvífica, de su vigencia. Y es que, en palabras del Arzobispo Montini,

viviendo en un tiempo tardo a la comprensión de los valores espirituales, tendemos a considerar a la Iglesia como un simple hecho humano, nos dejamos impresionar por aquellos que la clasifican como un fenómeno de otros tiempos, superfluo al menos para el progreso y la estabilidad del mundo civil moderno, y tal vez sospechamos, con el difundido laicismo contemporáneo, que sea usurpado, o al menos excesivo, el puesto que aún hoy la tolerancia civil o una ley estatal positiva le conceden a la Iglesia. (DsMS, 7/12/1958: 229)

En sus discursos y escritos no faltan tampoco admoniciones pastorales saliendo al paso de otras distorsiones - como el temporalismo, el conciliarismo, el clericalismo o el laicalismo- que generan confusión al interior del Pueblo de Dios, entre sus miembros, y evidencian malentendidos respecto a la comprensión de sus vocaciones y responsabilidades particulares (ver, por ejemplo, DSM I: 1468-1470; DsC, 88-96, 138-139, 162-165).

$4 \quad$ Así, por ejemplo: "Demasiados consideran a la Iglesia sólo en sus manifestaciones externas: su organización, la coherencia de su doctrina y de su moral, los frutos de perfección y de santidad (de martirio, en cada siglo) en aquellos que la aceptan plenamente, sus maravillosos veinte siglos de historia, su subsistencia sin la ayuda de las fuerzas humanas y a pesar del pecado en sus miembros e incluso, a veces, en su jerarquía, su caridad, la fuerza revolucionaria de su influjo en el mundo y en la civilización” (DsC, 1957: 8). 


\subsection{Signos de esperanza}

Los análisis que venimos recogiendo no deben llevarnos a suponer, sin embargo, que al Arzobispo Montini lo embargaba una visión pesimista o negativa que no le permitiera descubrir, al mismo tiempo, los elementos positivos que aquí y allá se vislumbraban. En su mente sin duda resonaban las palabras que Henri de Lubac plasmara en Catolicismo. Aspectos sociales del dogma, libro tan caro a G. B. Montini y en el que el jesuita francés apunta que "se anuncia ya la deseada primavera" en la Iglesia, "un renacer" que no consiste en "una simple agitación superficial", sino que "brota de las profundidades de la conciencia católica" (De Lubac, 1988: 225-226).

De entre algunas proposiciones en ese sentido, destacamos un discurso de 1955 en el que remarca que "precisamente en este último tiempo [en el campo de] la doctrina sobre la Iglesia, es decir sobre la sociabilidad religiosa generada por Cristo, los estudios se han desarrollado enormemente, y el magisterio de la Iglesia se ha pronunciado magníficamente" (DSM I, 30/8/1955: 372), y añadía esperanzado:

La conciencia de pertenecer a esta sociedad santa - santificadora y santificada-, a esta sociedad misteriosa — divina y humana-, a esta sociedad inmortal - perenne e histórica conjuntamente- apasiona a quien apenas la experimenta; el Sensus Ecclesiae fermenta en el espíritu con avidez por saber, por definir, por probar; y mientras el mundo moderno va inquietantemente perdiendo este Sensus Ecclesiae, distraído y ahogado en la profanidad de su vida temporal, en algunos, en vosotros, esta conciencia se despierta y se agudiza, e inmediatamente produce el deseo y casi el presagio seguro de una nueva, feliz plenitud de vida cristiana. (DSM I, 30/8/1955: 373)

Un par de años después, en 1957, el Arzobispo de Milán vuelve a detenerse en "los fenómenos dignos de mención [...] que documentan una poderosa vitalidad de la Iglesia" y que vienen marcando lo que considera

$5 \quad$ Ver también De Lubac, 1980: 187. Es conocido el gran aprecio que Mons. Montini le tenía al "eminente Jesuita Padre De Lubac" (DSM I: 669). Poco antes de ser elegido Pontífice, el 18/4/1962, le escribió una carta en la que le expresaba: "Leo siempre con mucho interés, y espero también con provecho, sus libros, si bien las obligaciones de mi ministerio no me dejan mucho tiempo para la lectura y muy poco para el estudio" (cit. en De Lubac, 2000: 237). En su magisterio episcopal lo cita en varias ocasiones (ver, por ejemplo, DSM I: 372, 669, 1404; II: 2154, 2662, 3261, 3463, 3464, 3756, 3757, 3904; III: 4847, 4911, 4918, 4987, 5287, 5709). Téngase en cuenta, además, que la traducción de Catolicismo al italiano fue llevada a cabo por la Editorial Studium (Roma 1948), tan cercana a G. B. Montini. 
un "maravilloso capítulo en la epopeya histórica de la Iglesia moderna". Entonces subrayó, entre otros elementos, esa capacidad de introspección que le permite conocerse a sí misma, sintonizar con las mociones del Paráclito y renovar su afán evangelizador:

La Iglesia, se podría decir, se inclina sobre sí misma bajo la inmensa pesadilla de la irreligiosidad moderna, y experimenta en este recogimiento interior, quiero decir, en este recurso a las fuentes de vida sobrenatural que contiene en sí, cómo se multiplica su confianza, su energía, su capacidad de conquista. Es el flujo del Espíritu Santo que invade incluso a sus miembros, y los hace ágiles y fuertes. Es el viento de Pentecostés, que sopla en las velas de la nave mística, que ya no teme a las tormentas. (DSM I, 9/6/1957: 1466; ver DsC: 175; DSM III: 5161-5162)

\section{AlgunAS RAÍCES DEL PROBLEMA}

Ahora bien, más allá de estos signos esperanzadores, ¿qué elementos pueden llevar a que quienes han recibido el sello del Bautismo no ponderen en toda su profundidad a aquella que ha sido designada como depositaria de los dones divinos, y no reflexionen agradecida y constantemente sobre su filiación divina y su pertenencia a la "comunión de los santos"? ¿Qué razones encuentra G. B. Montini que puedan dilucidar, al menos en parte, el fenómeno que hemos descrito?

Queremos comenzar recogiendo algunas de sus declaraciones que, si bien no ofrecen la explicación más acabada del problema, tienen la virtud de mostrar ese talante realista y existencial que caracterizaba su aproximación intelectual, aludiendo a cuestiones que no se suelen mencionar cuando se abordan asuntos como el que nos ocupa. Ya en torno a los años 1920-1921, en los apuntes de juventud que hemos citado, constataba la frágil naturaleza del hombre y la flaqueza de sus facultades, que se han visto afectadas como fruto del pecado: "Ya debería saber que la razón y la voluntad humana son instrumentos muy débiles, y que, si bien continúan ejerciendo su tarea y cumpliendo un trabajo inmediato, pierden con facilísima inconsciencia la dirección correcta de su movimiento" (Montini, 1994: 26). De ahí que el ser humano olvide fácilmente quién es, cuál es su razón de ser, de qué Cuerpo forma parte y qué elementos configuran su identidad cristiana.

Unas décadas más tarde, desde la sede milanesa, Mons. Montini enriquecerá esta consideración antropológica general con algunos matices gnoseológicos que ningún observador debe obviar a la hora de aproximarse a una realidad tan vasta y tan compleja como el Cuerpo Místico de Cristo. La primera de ellas es que "fácilmente modelamos una definición 
de la Iglesia de acuerdo a las condiciones subjetivas de nuestros espíritus, listos para proyectar sobre ella pros y contras, en función de ciertas condiciones particulares nuestras" (DsC, 10/11/1960: 104). De ahí que no sea extraño presenciar que, a tono con las corrientes en boga, a muchos se les desdibujen los perfiles de la comunidad eclesial. En segundo lugar, que "la Iglesia constituye un tema vivido, que compenetra nuestra vida y nuestro pensamiento. Pero, justamente por ello, podría ser menos conocido de forma refleja, y precisa, como tantas cosas que forman parte de nuestros hábitos y de nuestra naturaleza" (DSM II, 12/8/1959: 2973). Algo similar nos sucede con lo que tenemos más cerca de nosotros mismos, pues a fuer de esa cercanía perdemos perspectiva y se nos torna muy difícil percibir lo que para otros puede parecer evidente. $Y$, en tercer lugar, recogiendo una enseñanza de la "psicología religiosa" que se aplica a cualquier realidad mistagógica, que "para poder gozar de la luz, es necesario tener los ojos abiertos, y mucho más todavía si esa luz está envuelta por el misterio, como ocurre en nuestra vida presente" (DPM, 6/1/1958: 132) ${ }^{7}$. Es ésta una figura tomada de la física óptica que con mayor razón se aplica a las realidades espirituales: su percepción depende de la apertura de la mente y el corazón, de la disposición positiva de los sentidos interiores.

A ello se añade - como se esboza en la cita anterior y Mons. Montini no se cansa de repetir, revelándose como otro de sus distintivos eclesiológicos- que nos encontramos ante una institución espiritual y mistérica, cuyas categorías de comprensión se asientan en este mundo, pero se proyectan y alcanzan su verdadero sentido cuando se insertan en la Comunión Trinitaria. En efecto,

La Iglesia es un misterio. Esconde aspectos y verdades profundas, y la visión que ordinariamente tenemos de ella no es sino una visión de fachada. Creemos conocerla, porque conocemos el salón sagrado donde vamos a escuchar la Misa, porque conocemos a nuestro párroco, porque conocemos un poco del catecismo. Ciertamente, nadie discute que también esto sea la Iglesia. Pero si decimos que es toda la Iglesia, estaríamos equivoca-

6 Por ello recomienda allí mismo que es preciso "ser cautelosos al expresar opiniones apresuradas y sumarias al respecto, mientras que generalmente carecemos de esta honesta cautela, y aventuramos sentencias que deforman nuestra propia comprensión de este hecho grandioso que se llama Iglesia" (DsC, 10/11/1960: 104).

7 Poco antes exhortaba a sus oyentes: "Examinaos vosotros mismos sobre este punto: ¿encontráis despierta a vuestra conciencia? ¿Está dispuesta? ¿Desea la verdad o es, por el contrario, perezosa y decididamente adversa a ella, porque sabe que la verdad, una vez descubierta, resulta exigente con nosotros hasta marcarnos el camino a seguir? [...] Amad la verdad, porque ésta es la mejor disposición para encontrarla: 'quien busca hallará' (Mt 7,8)" (DPM, 6/1/1958: 132). 
dos. Observaríamos la portada, sin leer las páginas de este libro que permanece cerrado. Observaríamos la fenomenología humana, que se refleja en nuestra experiencia y en nuestra vida cotidiana, pero no veríamos toda la verdad, las fuerzas, el misterio que está detrás. [...] Creemos que conocemos a la Iglesia y, sin embargo, cada vez que aguzamos la mirada, descubrimos su profundidad. (DSM II, 12/8/1959: 2978-2979) ${ }^{8}$

No es de extrañar, pues, que no tengamos un conocimiento acabado del Cuerpo de Cristo, que nos sea imposible agotar la percepción de su naturaleza. Nuestra limitada capacidad humana siempre se verá desbordada por la inmensidad e infinitud de su misterio, que se remite en última instancia al ser de Dios.

Estas observaciones - lo apuntábamos ya-, evidentemente no agotan la explicación del fenómeno, pero resulta interesante descubrirlas en la propuesta montiniana, porque configuran una suerte de condiciones existenciales mínimas que no muchos tienen en cuenta, y de las que adolecen nuestros tiempos.

No se le escapan al Arzobispo de Milán, por otro lado, las particulares y contradictorias circunstancias culturales de aquellas décadas, que para él constituyen el núcleo y, a la par, intensifican el problema. Nos referimos a los diferentes "ismos" que signan el ambiente ideológico e intelectual de aquellos años — como el "racionalismo, iluminismo, naturalismo, agnosticismo, idealismo, existencialismo, y hoy, en la práctica, el laicismo y el ateísmo" (DSM I, 24/2/1957: 1220-1221) ${ }^{9}$, que ciertamente en varios momentos examina, pero sobre los que no nos detendremos por resultar menos novedoso en su análisis-. Como apunta en sus escritos, todos ellos han contribuido, cada uno a su modo, a este opacamiento en los creyentes de su conciencia e identidad. Y ello lo lleva a constatar que se vive un tiempo con poca permiabilidad hacia los valores espirituales, en el que se tiende a eliminar del horizonte aquello que no es palpable o tangible, que rechaza las realidades meta-físicas y sobrenaturales por pertenecer a cosmovisiones "ingenuas" y pre-científicas, y en el que se difunde una actitud corrosiva que parece disolver toda certeza e impugnar cualquier búsqueda de la verdad. Estos prejuicios suspicaces y aprensivos se acentúan aún más cuando de realidades espirituales o religiosas se trata. En efecto, "el desarrollo de la vida moderna parece volverse en su contra, por la incredulidad que profesa, por la ilusión de sufi-

8 La categoría de "misterio", como anotábamos líneas arriba, ocupa un lugar destacado en la eclesiología montiniana. Ver, por ejemplo, DsC: 8, 111-120, 156-157, 220-221; DSM I: 1662-1683; DsMS: 273-281; etc.

Ver, además, entre otros, DSM III: 4393; DsMS: 195, 229; Carta al Papa Juan XXIII, 22/12/1959, en Capovilla, 1982: 116. 
ciencia que crea en el hombre, por el laicismo y el ateísmo, que parecen caracterizar con sombrías energías la espiritualidad, cada vez más agnóstica y materialista del humanismo contemporáneo" (DSM I, 9/6/1957: 1466).

Más allá de estas consideraciones antropológicas, gnoseológicas y culturales, G. B. Montini se fija asimismo en otros elementos que abonan, y de forma significativa, en el oscurecimiento de la conciencia eclesial, pero esta vez concernientes a la vida de la Iglesia propiamente dicha. Nos referimos, por ejemplo, a "dos problemas característicos de nuestro tiempo, el de la autoridad y el de la relatividad". Respecto al primero, muy ligado a la exacerbación de la libertad que cuestiona cualquier límite, "se impugna la constitución jerárquica de la Iglesia, o allá se critica y allá se desautoriza, a veces incluso por parte de algunos que todavía quieren decirse fieles, pero que en la práctica y a veces también mediante razonamientos orgullosos, desdeñan obedecerla con franca cordialidad, y acusan más la molestia de su disciplina". Mientras que el segundo —el de la relatividad - es tanto un síntoma como un germen que deriva en la pérdida de identidad, y se manifiesta en que "a otros les gustaría que la Iglesia fuese más conforme, más relativa a la historia, es decir, que se adapte a los tiempos, esto es, a las ideas, intereses y costumbres actuales; incluso en lo que las vicisitudes presentes tienen de contingente y precario, e incluso cuando esta adaptación implicaría infidelidad a la palabra y al mandato de Cristo" (DSM III, 10/6/1962: 5161; ver III: 5711-5712).

Ese mismo deseo de adaptación asoma como un peligro sobre su misión evangelizadora - ya sea pastoral, ecuménica o ad gentes- y lleva en no pocos a "confundir el diálogo con los indiferentes, los alejados y los adversarios, con la asimilación de su manera de pensar y de obrar. En este caso - subraya el Cardenal-, no seríamos ya unos conquistadores, sino unos conquistados". Y es que "el diálogo, método necesario para el apóstol, no debe cerrarse con una negación u olvido de nuestra verdad en beneficio del error o de la verdad parcial que en un principio se quería redimir", sino que tiene que conducirse desde el inicio con una clara y firme conciencia de la propia identidad. Lejos de la intención del Arzobipo Montini el querer desalentar con estas palabras en alguna medida el ardor apostólico en cualquiera de sus manifestaciones. Al contrario, lo que pretende más bien es inflamarlo, pero evitando un "equívoco sobre esta materia [que] es tentador en nuestros días" y que traería consigo frutos negativos: "podría restar fuerza a nuestra actuación, diluyéndola en un sincretismo híbrido de ideas y de métodos y podría acostumbrar al católico militante a un conformismo oportunista y servil. La sal sin sabor no sirve para nada" (DPM, 6/1/1960: 154; ver SF: 69). Era ése, en efec- 
to, un problema que se venía verificando en la acción apostólica de aquellos años, y que lamentablemente vemos acentuado en nuestro tiempo.

\section{LA ESTRATEGIA PASTORAL DE MONS. MONTINI}

Todos estos análisis y diagnósticos, sin embargo, no se quedan simplemente en una denuncia o un llamado de atención, sino que se traducen en una estrategia diseñada por el Arzobispo Montini para hacer frente a este complejo y multifacético problema que contempla asimismo diferentes dimensiones.

Quizá lo primero que habría que destacar es que el espíritu que anima todo su plan está lejos de traslucir una actitud pasiva, defensiva o retraída. Al contrario, convencido de que Jesucristo ha venido para que tengamos "vida en abundancia" (Jn 10,10), y de que la Pascua nos abre las puertas a la verdadera plenitud humana, Mons. Montini nos invita a descubrir la alegría de la fe, la bendición del llamado a formar parte de la Iglesia, la excelencia del camino cristiano. Lo que él quiere es "presentar al mundo un cristianismo admirable, atrayente, simpático" (DSM I, 9/10/1957: 1681), no como una táctica engañosa para ganar más adeptos, sino como la recuperación de un axioma constitutivo de la vida cristiana que debe signar a todo creyente y que ha de traslucirse, contagiante, en su existencia cotidiana. En ese sentido deben comprenderse sus diversos afanes apostólicos, con los que busca estimular "una renovación pastoral orientada sobre todo al cambio de mentalidad de los responsables de la pastoral" (Giovagnoli, 2004: 179). Si los apóstoles no son los primeros convencidos, poco se podrá lograr.

No podemos dejar de mencionar, por otro lado, su permanente llamamiento a fijar la mirada en Jesucristo -en consonancia con el cristocentrismo que signa todo su pensamiento teológico y eclesiológico ${ }^{10}$ - ni sus exhortaciones a fortalecer la vida espiritual - en consonancia con su convencimiento de que la dimensión mística y sobrenatural de la Iglesia subyace a su estructura jurídica y social, por lo que la oración es también la base de cualquier acción apostólica ${ }^{11}$ - , cuestiones nucleares de su proyecto evangelizador y que componen el marco más amplio en el que se encuadran sus propuestas. Pero sobre ellas tampoco nos vamos a de-

10 Como apunta E. Manfredini, "la fe en Jesucristo es el centro que unifica la vida y la misión episcopal del Card. Montini en Milán" (1985: 63). D. Marzaroli, por su parte, añade que "el principio teológico inspirador de la eclesiología montiniana es sin duda el cristocentrismo" (1997: 198). Ver, por ejemplo, DSM I 23ss.; II: 2045-2046; III: 4218, 4291, 4491, 5713-5720; etc.

11 Ver, por ejemplo, DSM I: 254-255, 425, 781-782, 899, 946, 1417; II: 2840-2841; etc. 
tener. Creemos oportuno, más bien, subrayar por su peculiaridad otras de sus propuestas.

\subsection{Invitación a renovar la conciencia y llamado a la coherencia}

En primer lugar, Mons. Montini no se cansó de invitar a que cada bautizado profundice en su propia identidad y redescubra la riqueza que entraña la vocación cristiana. Con una asiduidad que podríamos calificar de sana "obsesión”, “intencionalmente el arzobispo se preocupó, más que por resaltar algún aspecto particular del ser cristiano, por despertar en los cristianos la conciencia de serlo, con la gran dignidad que ello conlleva y las responsabilidades resultantes" (Xeres, 2004: 81). A partir de allí, además, los convocó firme y convencidamente, con la misma perseverancia, a una vida coherente que reflejara en su quehacer cotidiano sus convicciones interiores. $\mathrm{Y}$ es que, como hacíamos notar líneas arriba, para él la conciencia debía necesariamente reflejarse en la vivencia, sin la cual resultaría cuando menos incompleta.

Así lo repite de diversas formas y en distintas circunstancias de su ministerio episcopal. Por ejemplo, en 1955, en el ya referido inicio de sus visitas pastorales a las parroquias milanesas, observa que "nuestro tiempo necesita de verdaderos cristianos", y por ello insta a que procuremos "recuperar la conciencia de lo que es la vida cristiana; [...] es decir, el saberse cristianos, el saberse llamados, el saberse elegidos, el saberse destinados a grandes cosas en el pensamiento de Dios, el saberse responsables, en esta vida, de nuestro tiempo, de nuestros hermanos, el saberse responsables de una inmensa y eterna vida futura" (DSM I, 8/9/1955: 397 y 392 $)^{12}$. Unos meses después, en su primera Misa de Navidad como Arzobispo, insiste en que es preciso que los signados por el Bautismo “demos al término 'cristiano' la gloria y la energía que debe encerrar en sí mismo: que seamos capaces de vivir una vida auténticamente cristiana" (DPM, 25/12/1955: 25), ya que, como enfatiza al año siguiente, "hay una necesidad de interioridad, hay una necesidad de reflexionar sobre uno mismo, hay una necesidad de vivir interiormente, quizás más que ayer, mejor que ayer" (DSM I, 4/9/1956: 946). De ahí ha de brotar, como corolario, el "renovado propósito de adecuar nuestra vida a nuestra vocación cristiana", por lo que no duda en exclamar: "Cristianos, sed cristianos. [...]

12 En esa misma ocasión hace hincapié en que "recuperemos la conciencia de lo que significa ser cristianos" (DSM I: 393), "alentémonos todos juntos el no ser inconscientes, el no ser insensibles, el no ser personas que traicionan la vocación cristiana" (DSM I: 394) y "tratemos de recuperar la verdadera conciencia de nuestra vida cristiana. Agnosce, christiane, dignitatem tuam, dice San León. 'Conoce, oh cristiano, ante todo tu dignidad"” (DSM I: 395). 
La exhortación ya no es un reproche, es un augurio, es consuelo: cristianos, jsed cristianos!" (DSM I, 1/4/1956: 720; PNA: 57).

Evidenciando la importancia que le concedía a esta exigencia, en términos similares se pronunciará en 1957: "Ha llegado el momento de renovar en nosotros la conciencia de que somos cristianos" (DSM I, 12/1/1957: 1153). Dos años después, esta vez en la celebración de la Epifanía de 1959, volverá a apremiar a los católicos a que tomen "conciencia no sólo de lo que son - a esta conciencia podríamos llamarla 'sentido católico'-, sino también de lo que deben ser - y a esta conciencia podríamos llamarla 'sentido de la catolicidad'-" (DPM, 6/1/1959: 140). Y otros dos años después, con ocasión de las fiestas pascuales de 1961, recalcará con gravedad que los creyentes deben dar testimonio de una vida de fe luminosa, intensa y fecunda:

Creo que esto, queridos hijos, es importante para nosotros hoy. Cristianos, debemos dar a este título un contenido más pleno y más coherente. Nuestro cristianismo debe derivar de sus raíces sobrenaturales, la fe y la gracia, una expresión más clara y más fuerte. Con demasiada frecuencia nuestro cristianismo es simplemente nominal y formal; y entonces se vuelve contra nosotros; se convierte en pesado al soportar alguna observancia sobreviviente; se convierte en responsabilidad y no en energía, se convierte en acusación por parte de quienes lo ven en nosotros mismos débil, inobservado y quizás traicionado. Nuestro mundo, en cambio, necesita un cristianismo verdadero y operante; necesita cristianos que vivan, en la fe y en las costumbres, su bautismo. (PNA, 1/4/1961:166) ${ }^{13}$

$\mathrm{Y}$ es que, como señala en otro momento explicando justamente los fundamentos sacramentales que tiene este requerimiento, "quien es cristiano debe vivir como cristiano. Por encima de esta adhesión, por encima del plan de salvación en el que hemos entrado, debemos darle estilo a nuestra vida, debemos conformarla. No podemos vivir así, como los demás, o con la libertad caprichosa e indisciplinada de quienes no tienen ni fe ni Bautismo". Más bien, en consonancia con nuestra impronta sacramental, "hemos de derivar nuestra vida de la fe, iustus ex fide, y según los compromisos que hemos asumido en el Bautismo. [...] Hemos de repetir las promesas bautismales con gran franqueza y con energía, deben ser la huella de un programa de vida coherente y noble" (DSM III,

13 Poco antes había precisado: "El cristiano no es en realidad y no debe ser en la práctica como un hombre que no tiene la fortuna de portar tal nombre. El cristiano debe ser diferenciado de las costumbres profanas y paganas que lo circundan. El cristiano debe saber inmunizarse del ambiente irreligioso e inmoral que el mundo, ígnaro de Dios y de Cristo, crea a su alrededor..." (PNA, 1/4/1961: 165). Ver también DSM I: 995; III: 4065 y 4962. 
27/3/1961: 4221). Aquí se engarza, como puede apreciarse, su también insistente llamado a que todos tomemos renovada conciencia del sacramento bautismal, otro acento peculiar de su enseñanza milanesa ${ }^{14}$.

De lo que se trata finalmente, como subraya en 1962, es de adherirnos de tal modo al Señor Jesús que podamos reflejarlo en una sociedad que se muestra tan necesitada de Él: "Apreciemos este título de 'cristianos', que no sólo nos refiere a Cristo, sino que nos liga y nos une; sintamos la profundidad y la dignidad, démosle vigor de compromiso y de fidelidad, disfrutemos la alegría y la confianza, porque precisamente Cristo nos quiere cristianos así hoy, y a ser así hoy nos ayuda" (PNA, 21/4/1962: 187).

\subsection{Conocer, amar y despertar el anhelo por pertenecer a la Iglesia}

Otra vía original que propone Mons. Montini hace referencia directa a la comunidad eclesial. Lo que quiere es "volverle a dar a la Iglesia su importancia en nuestra espiritualidad, en nuestra concepción religiosa, en nuestro catolicismo activo" (DsC, 26/4/1959: 74) $)^{15}$. Para ello considera que es preciso cultivar una triple actitud, y aquí su propuesta contempla una perspectiva integral, como es característico en su magisterio y en su labor pastoral.

En primer lugar, a nivel intelectual plantea la exigencia de profundizar en el misterio de la Iglesia ${ }^{16}$, a la que hemos sido incorporados por el don del Bautismo y sin la que no podemos comprender nuestra identidad cristiana. Serán numerosas las ocasiones en que Mons. Montini abordará este argumento. Así, por ejemplo, en 1958, observará: "Si queremos ser católicos, debemos ser capaces de reelaborarnos un concepto más exacto de la Iglesia, y no debemos dejar de descubrir, al menos de alguna manera, el misterio que ella porta consigo" (DsMS, 7/12/1958: 229). Al año siguiente, en agosto de 1959, en la sede del Seminario de Varese, aconsejará a un grupo de jóvenes: "Buscad profundizar, comprender a la Iglesia, redescubrirla, y veréis que tendréis manantiales verdaderamente entusiasmantes y refrescantes". Es una tarea que exige paciencia, dedicación, pero que siempre trae consigo abundantes frutos, ya que —como lo

14 Ver, por ejemplo, DSM I: 395, 716, 718; II: 2175, 3010; III: 4213-4221; etc.

15 Como recalca sintéticamente G. Rumi, "no se debe olvidar cuán importante fue para Montini la Iglesia. [...] Montini creía en la Iglesia, la amaba, la servía” (2004: 174).

16 Este punto se enmarca en el más amplio de la formación en las verdades cristianas, pues "el enemigo capital de la fe es la ignorancia: y en ese caso es absolutamente necesaria la instrucción religiosa" (DSM I, 9/3/1957: 1253), ya que "un cristiano ignorante no puede ser un verdadero cristiano. [...] Para ser conscientes se requiere ser instruidos" (DSM II, 9/7/1958: 2219). Ver también DSM I: 198-199. 
evidencia la historia y se lo ha mostrado su propia experiencia- "creemos que conocemos a la Iglesia y, sin embargo, cada vez que aguzamos la mirada, descubrimos su profundidad. Este prodigio se produce siempre" (DSM II, 12/8/1959: 2980 y 2979) ${ }^{17}$. Por ello a fines de 1960, en la conferencia introductoria a la Misión de Florencia, volverá sobre el tema y reiterará que, especialmente en nuestro tiempo,

es necesario volver a comprender a la Iglesia. Esta necesidad era menos sentida cuando se vivía habitualmente en la Iglesia, y de la Iglesia se hacían propios el pensamiento y las costumbres; ahora que la Iglesia se ha convertido en objeto de contestación, y que, al menos en la práctica, ha sido desterrada de la mentalidad moderna, de la concepción profana de la vida, para volver a entrar en sus recintos conscientemente, o incluso simplemente para justificarse a sí mismo el abandono de aquella antigua casa paterna, es preciso volverse a dar un concepto reflejo, más preciso, más esencial de la Iglesia. Y esta necesidad no es menos grave y urgente para quien tiene la fortuna de vivir serenamente en la casa espiritual de sus antepasados. (DsC, 10/11/1960: 104-105; ver DSM III: 5160)

Para el futuro Pontífice no se trata, sin embargo, de un ejercicio que deba circunscribirse única o prioritariamente al ámbito especulativo. Resulta indispensable complementar dicho esfuerzo con un segundo movimiento: una labor cordial, afectiva. Al respecto, son también abundantes las veces que invita a cultivar sentimientos de afecto hacia nuestra " $\mathrm{Ma}$ dre" (DsC, 10/11/1960: 124-125). Así se lo formula enfáticamente, por ejemplo, casi al inicio de su ministerio episcopal, a un grupo del Movimiento de Graduados de la Acción Católica:

Vosotros estudiáis a la Iglesia. Pues bien, no es suficiente. La estudian también aquellos que no se llaman hijos. La estudian también sus adversarios. Y la estudian también muchos buenos católicos. Pero se detienen en el estudio. [...] Es necesario, sin embargo, no sólo estudiar a la Iglesia; es necesario sobre todo amar a la Iglesia. Amar a la Iglesia como la amó Nuestro Señor: Dilexit Ecclesiam. (DSM I, 30/8/1955: 373-374)

Y así lo repite poco antes de asumir el oficio de Pedro: "No sólo advertimos el deber y la necesidad de conocer mejor a nuestra Iglesia, sino

17 En esa misma circunstancia se pregunta cómo puede uno ahondar en el misterio de la Iglesia, y responde: "Hay cuatro caminos para conseguirlo, y son las famosas cuatro notas, es decir, los cuatro aspectos de la Iglesia, que se revela apostólica, una, santa y católica. [...] Todas estas notas nos dan una visión brillante, asombrosa; si profundizamos en ellas y buscamos el porqué, nos encontramos frente a la teología de la Iglesia” (DSM II, 12/8/1959: 2980). 
que sentimos un deber y una necesidad no menos apremiante de amarla. ¡Amar a la Iglesia!” (DSM III, 10/6/1962: 5162) ${ }^{18}$. Un amor que, al mismo tiempo, nos llevará a una unión más íntima con quien es su Fundador y Cabeza, el Señor Jesús, y nos ayudará a transformarnos en Él. En efecto, "cuanto más amamos a la Iglesia, más amamos a Cristo y asumimos su 'forma'. Y cuanto más buscamos a Cristo, por encima y dentro de la envoltura humana de la Iglesia, más nos convertimos en auténticos eclesiásticos, que quisiéramos y deberíamos ser" (DSM III, 7/4/1963: $5710)^{19}$. Un amor, en fin, que incluso frente a sus deficiencias humanas no nos quita objetividad ni nos encierra en un «lirismo ideal», sino que se convierte en "deseo de ayudarla, de remediar sus males. Si la Iglesia fuera una gran enferma, tendríamos que aprender a amarla asî" (DSM I, 30/8/1955: 374). Gran lección para nuestro tiempo, sobre la que vuelve en otras ocasiones ${ }^{20}$. Por ello no se cansa de decir: “AAmad a la Iglesia! [...] Pensad cómo está constituida y cómo está hecha, buscad comprenderla y conocerla, buscad que cuando celebréis los santos ritos y las plegarias, tengáis también vosotros la alegría de ser Iglesia" (DSM II, 28/2/1960: 3396; ver I: 199).

Finalmente, como lógica consecuencia y corroboración de estas actitudes para con el Cuerpo de Cristo, a la hora de ejercer sus tareas evangelizadoras todos los bautizados han de desarrollar a la par una praxis eclesial. Junto al "ansia de dilatar el reino de Dios, de comunicar a los demás hombres los tesoros de fe y de caridad que Él nos ha dado", de-

18 Vale la pena leer los siguientes párrafos de esta homilía, en los que detalla la manera como debe darse ese amor.

19 Si bien el término "ecclesiastici" se aplica en este pasaje concretamente a los sacerdotes (este texto es una carta dirigida a ellos), siguiendo a Orígenes y a su "esse ecclesiasticus" -tema tan valorado por Mons. Montini-, también puede entenderse como referido a todos los bautizados en general.

20 Aprovechando el testimonio de San Ambrosio y de San Agustín, invita a replicar su actitud frente al Cuerpo de Cristo: "Lección para nosotros esta imperturbable actitud de vislumbrar el estupendo elemento divino de la Iglesia, siempre irradiante incluso desde un elemento humano deforme; lección para nosotros los modernos, que estamos tan dispuestos a hacer lo contrario, es decir, descubrir los defectos humanos de la Iglesia, incluso cuando su comunidad mortal nos ofrezca signos indudables de su vitalidad espiritual y de su arcana belleza; lección para nosotros, que movidos a veces por un honesto pero incompetente deseo de reconducir la vida práctica de la Iglesia a una conformidad más evidente con los preceptos evangélicos, o estimulados por el inquieto espíritu reformador de nuestro tiempo reformador, nos autorizamos a adosar a la Iglesia la culpa de los males del mundo, o a denunciar con complacencia y con desdén los defectos de algunos de sus hijos, o a criticar con sutil ironía las formas exteriores con las que se viste, o a negarle, bajo un respeto formal, obediencia y confianza, con suficiencia arrogante, donde la verdad, amarga y parcial, apaga la caridad, interrumpe la comunión" (DsMS, 7/12/1958: 228-229). 
ben asimismo "despertar en ellos el ideal de la Iglesia y la añoranza de pertenecer a ella" (DPM, 6/1/1960: 152). Nótese la singularidad de la propuesta: no se trata solamente de anunciar el reino de los Cielos o de predicar el Evangelio, sino también de plantear la noción de la Iglesia y de suscitar el anhelo por formar parte de dicha comunidad de los redimidos. Así se verifica, además, la coherencia de la conciencia bautismal, que para Mons. Montini sólo está completa, como hemos insistido, si es que se hace vida en el día a día de la existencia. En la eclesiología montiniana, quien se sabe bendecido por haber sido incorporado al Pueblo de Dios, quien descubre en la Iglesia un espacio de realización y de encuentro con Dios, no puede permanecer inactivo y ahorrarse esfuerzo alguno a fin de que todos puedan integrarse a ella.

\section{PROYECCIONES Y CONCLUSIONES}

Luego de haber repasado someramente el magisterio episcopal del Arzobispo Montini, hemos podido constatar cómo el futuro San Pablo VI tenía una clara idea de la situación que enfrentaba: los hijos de la Iglesia - envueltos en unas cambiantes y desafiantes circunstancias marcadas por el relativismo, el racionalismo, el laicismo, el indiferentismo religioso y la creciente secularización-, fueron perdiendo conciencia del Cuerpo del que son miembros y de su condición de bautizados, vieron opacada su índole católica y por ello diluido su talante particular, fueron mimetizándose con los criterios y valores del mundo, fueron olvidando las verdades fundamentales que conforman el depósito sagrado, disminuyendo al mismo tiempo sus convicciones religiosas y su ardor evangelizador.

Como lo evidencian sus repetidas y continuas intervenciones al respecto - con diagnósticos, análisis de la realidad, llamados de atención, exhortaciones pastorales y planes de solución que recorren todo su servicio episcopal, desde que tomó posesión de la sede milanesa hasta pocos días antes de ser elegido Sumo Pontífice-, esta problemática representaba para él uno de los principales desafíos apostólicos que debía abordar en su ministerio. La multifacética estrategia evangelizadora que diseñó para hacerle frente no hace sino indicar la proporcional importancia que le atribuía.

Entre las distintas iniciativas que emprendió, destacan su interés por darle un nuevo brillo a la condición de cristianos, invitando constantemente a que dejemos de lado cualquier actitud timorata, retraída u opacada y reconozcamos más bien la altísima dignidad y la bendición que tal nombre comporta. De ahí también su insistencia por recobrar la apercepción de lo que implica el sacramento bautismal, por el que recibimos la condición de hijos en el Hijo y de miembros de la Iglesia. De acuerdo 
a su concepción teológica se trata, por lo demás, de una toma de conciencia que, para estar completa y ser plena, ha de volcarse ineludiblemente en una vida cristiana coherente y comprometida.

Otra particularidad de su propuesta que merece ser destacada es su inclusión de la misma Iglesia en el diseño de una respuesta integral que, en consonancia con esta compleja problemática, procure profundizar en el misterio de la Iglesia, avivar un hondo y filial amor a ella y multiplicar los esfuerzos evangelizadores a fin de que cada día sean más quienes perciban el anhelo interior de pertenecer a esta comunidad santificante y salvadora. Con ello evidencia que la Iglesia no es una realidad añadida o supererogatoria a nuestra índole de cristianos, sino que forma parte medular e irrenunciable del camino de la fe, al tiempo que manifiesta con tono existencial que, lejos de constituir una especie de lecho de Procusto, responde a los anhelos más hondos de la naturaleza humana.

Más allá de las adaptaciones que naturalmente merecen y no obstante los años transcurridos, los diagnósticos, la identificación de las raíces y las propuestas de solución esbozadas por Mons. Montini nos ofrecen sugerentes iluminaciones teológicas y pastorales. Como entonces, también hoy es preciso renovar la conciencia del Bautismo y sus efectos en todos los creyentes, fomentando en ellos la percepción alegre y agradecida de haber sido signados con el carácter sacramental e incorporados al Cuerpo de Cristo. Como entonces, también hoy se requiere invitar a los cristianos a que sean auténticamente cristianos, a que reconozcan su dignidad, fortaleciendo la coherencia entre su ser, su aparecer y su actuar, es decir, alentándolos a una genuina vida cristiana. Como entonces, también hoy urge conocer a la Iglesia, amarla a pesar de la iniquidad y los pecados de sus hijos, y despertar en todos los hombres el vivo deseo por ser contados entre sus miembros.

Al contemplar el panorama actual se puede percibir que el sopor en los hijos de la Iglesia y su consiguiente mimetismo con el mundo continuó a lo largo del pontificado del propio Pablo VI, no se atenuó a pesar de los esfuerzos doctrinales y pastorales del Concilio Vaticano II, se prolongó en el de sus sucesores y sigue alzándose hoy en día como uno de los grandes desafíos que tiene que enfrentar la comunidad eclesial en el siglo XXI. Afortunadamente las enseñanzas aportadas por G. B. Montini se presentan como una extraordinaria cantera, no sólo para entender mejor el problema, sino también $-\mathrm{y}$, sobre todo- para elaborar caminos de solución que nos permitan vivir cada día más de acuerdo con nuestra vocación y misión. 


\section{REFERENCIAS}

Acerbi, A. (1996). Giovanni Battista Montini, arcivescovo di Milano. En E. Guerriero, La Chiesa in Italia. Dall'unità ai nostri giorni (pp. 453-476). Cinisello B.: San Paolo.

Adornato, G. (2002). Cronologia dell'episcopato di Giovanni Battista Montini a Milano (4 gennaio 1955-21 giugno 1963). Roma-Brescia: Istituto Paolo VI - Edizioni Studium.

Adornato, G. (2018). Giovanni Battista Montini - Paolo VI. Biografía storica e spirituale. Torino: San Paolo.

Airò, A. (2001). Venite e ascoltate. Montini e la missione di Milano. Milano: Centro Ambrosiano.

Alzati, C. (2006). L'Arcivescovo Montini e la pastorale liturgica. En Centro Azione Liturgica, Celebriamo Gesù Cristo, speranza del mondo (pp. 69-84). Roma: CLV.

Biffi, I. (1987). L'activité liturgique de l'archevêque Montini. En Le rôle de G.B. Montini-Paul VI dans la réforme liturgique (pp. 32-58). Brescia: Istituto Paolo VI.

Bressan, L. \& Maffeis, A. (Dirs.). (2017). Montini. Arcivescovo di Milano. BresciaRoma: Istituto Paolo VI - Edizioni Studium.

Calderón, C. (1963). Montini, Papa. Salamanca: Ediciones Sígueme.

Calderón, C. (1965). Semblanza de Pablo VI. En Instituto Social León XIII, El diálogo según la mente de Pablo VI (pp. 81-108). Madrid: BAC.

Campanini, G. (2000). La missione milanese dell'Arcivescovo Montini (1957). Notiziario Istituto Pablo VI 39, 36-49.

Capovilla, L.F. (Ed.). (1982). Giovanni e Paolo. Due Papi. Saggio di correspondenza 1925-1962. Brescia-Roma: Istituto Paolo VI - Edizioni Studium.

Caprioli, A. \& Vaccaro, L. (dirs.). (1989). Lavoro ed economía ad G.B. Montini Arcivescovo di Milano. Brescia: Morcelliana.

Cioli, G. (1995). Coscienza ecclesiale, conversione e agire morale. Rapporto fra ecclesiologia e conversione nel magistero di Paolo VI. Firenze-Roma 1995: Pontificia Università Gregoriana.

Crivelli, L. (2002). Montini Arcivescovo a Milano. Un singolare apprendistato. Cinisello Balsamo: San Paolo.

De Giorgi, F. (2015). La laicità nel magistero dell'arcivescovo Montini. En A. Canavero \& D. Saresella (Dirs.), Cattolicesimo e laicità (pp. 161-182). Brescia: Morcelliana.

Formenti, V. (1983). "I lontani" nel magistero e nell'opera pastorale del Card. Giovanni Battista Montini, arcivescovo di Milano (1955-1963). Roma: Pontifica Università Lateranense.

Hera, E. de la. (2002). La noche transfigurada. Biografía de Pablo VI. Madrid: BAC.

Kadzinski, T. (1998), Giovanni Battista Montini arcivescovo di Milano maestro del clero (1954-1963). Roma: Università Pontificia Salesiana.

Lubac, H. de (1980). Meditación sobre la Iglesia. Madrid: Ediciones Encuentro. 
Lubac, H. de (1988). Catolicismo. Aspectos sociales del dogma. Madrid: Ediciones Encuentro.

Lubac, H. de (2000). Memoria en torno a mis escritos. Madrid: Ediciones Encuentro. Majo, A. (Dir.). (1983). G.B. Montini Arcivescovo. Milano: NED.

Manfredini, E. (1985). Le scelte pastorali dell'arcivescovo Montini. En G. Camadini (Ed.), Giovanni Battista Montini Arcivescovo di Milano e il Concilio Ecumenico Vaticano II (pp. 46-135). Brescia-Roma: Istituto Paolo VI - Edizioni Studium.

Manzoni, G. E. (1997). Montini a Milano. Le sfide della modernità. Humanitas 5-6, 775-784.

Marzaroli, D. (1997). Pablo VI, artífice y exegeta de la eclesiología postconciliar. Ecclesia. Revista de Cultura Católica, 2, 195-218.

Montini, G. B. (1962). Discorsi su La Chiesa (1957-1962). Milano: Arcivescovado di Milano.

Montini, G. B. (1965). Discorsi su la Madonna e su i santi (1955-1962). Milano: Arcivescovado di Milano.

Montini, G. B. (1969). Dios presente en el mundo. Navidad y Epifania (Homilias, 1955-1961). Salamanca: Sígueme.

Montini, G. B. (1979). Scritti giovanili. Brescia: Queriniana.

Montini, G. B. (1994). Note giovanili. Notiziario Istituto Paolo VI, 27, 7-36.

Montini, G. B. (1997-1998). Discorsi e scritti milanesi (1954-1963), I. 1954-1957. II. 1958-1960. III. 1961-1963. IV. Appendice e Indici- Brescia-Roma: Istituto Paolo VI - Edizioni Studium.

Montini, G. B. (2004). Scritti fucini (1925-1933). Brescia-Roma: Istituto Paolo VI - Edizioni Studium.

Montini, G.B. (2010). Pasqua: la novità dell'amore. Omelie del triduo e scritti pasquali. Milano: Centro Ambrosiano.

Pizzonia, C. (1981). L'identità del cristiano nel pensiero di Paolo VT (1965-1968). Roma: Pontificia Facoltà di Scienze dell'Educazione.

Poli, G. F. \& Crespi, P. (1998). Giovanni Battista Montini. Il magistero sulla vita religiosa (1955-1963). Soveria Mannelli: Rubbettino.

Potestà, G. L. (1988). L’episcopato di G.B. Montini a Milano (1955-1963). En G. Alberigo (Ed.), Chiese italiane e Concilio (pp. 91-128). Genova: Marietti.

Seveso, B. (1989). "Amore che grida". L'esistenza pastorale dell'arcivescovo Montini. Ambrosius, 45(1), 22-337.

Tettamanzi, D. (2009). Paolo VI. L'Arcivescovo Montini raccontato dal suo terzo successore. Torino: San Paolo.

Tornielli, A. (2009). Paolo VI. L'audacia di un Papa. Milano: Mondadori.

Vaccaro, L. (Dir.). (2004). Il cristiano laico. L'eredità dell'arcivescovo Montini. Brescia: Morcelliana.

Valtolina, A. (1999). Chiesa e modernità: l'esperienza di Giovanni Battista Montini a Milano (1954-1963). Milano: Università Cattolica del Sacro Cuore.

Xeres, S. (2004). «Cristiani, siate cristiani!». Esortazioni dell'Arcivescovo Montini ai fideli comuni. En L. Vaccaro (Dir.), Il cristiano laico. L'eredità dell'arcivescovo Montini (pp. 81-100). Brescia: Morcelliana. 